\title{
The Effect of Biofertilizers on Growth and Yield of Legumes - A Review
}

\author{
Hardika Kaushal $^{1 *}$ and Sarvjeet Kukreja ${ }^{2}$ \\ ${ }^{1}$ Department of Agronomy, School of Agriculture, Lovely Professional University, \\ Jalandhar, Punjab 144411, India \\ ${ }^{2}$ Lovely Professional University, Jalandhar, Punjab 144411, India \\ *Corresponding author
}

\section{A B S T R A C T}

\section{Keywords}

Biofertilizers,

Rhizobium,

Phosphate

Solubilising

Bacteria,

Azotobacter,

Azospirillum,

Mycorrhiza

Article Info

Accepted:

20 October 2020

Available Online:

10 November 2020
Legume crops are important because of its market and nutritional value. They have the ability to fix the atmospheric nitrogen. If a legume is sown in the field it can provide nitrogen for the successive crop because of the amount of nitrogen it fixes during its growth. Due to excessive use of the chemical fertilizers the microbial population can decline in the soil. These microbes are important for converting the unavailable form of nutrient into available form. Biofertilizers contain these beneficial micro-organisms which are applied to the seed or to the soil. These micro-organisms then form association with the plants and helps changing the organic form into inorganic form of nutrient. This is a sustainable method and can also help improve soil quality.

\section{Introduction}

In the modern era of agriculture, the use of chemical fertilizers has increased tremendously over the period of time. Farmers were drawn to chemical fertilizers because the release of nutrients was faster than the traditional manures and were cheaper comparatively. During the Green revolution, in India use of chemical fertilizers was promoted to increase the yield of crops. Using chemical fertilizers showed positive effects and the production of crop was increased. The dependence on chemical fertilizers has increased due to increase in food demand as a result of increased population. The pressure to feed billions of people and meeting the food demand encouraged the use of chemical fertilizer due to its rapid release nature and as it was easily available. The excessive uses of chemical fertilizers in agriculture are costly with adverse effects on physico-chemical properties of soils (Ghany et al., 2013). The uses of chemical fertilizers have some major disadvantages such as toxic residual effect. The chemical fertilizer produces toxic 
residual substances which alters the health of the soil. The micro organisms living in soil which also affect the plant life and are beneficial to the plants are also killed due to high amount of fertilizers. The indiscriminate use of synthetic fertilizer has led to the pollution and contamination of the soil, has polluted water basins, destroyed micro organisms and friendly insects, which makes the crop more prone to diseases and reduces soil fertility (Mishra et al., 2012). The absence of soil micro-organism affects the growth of the plant as these microorganisms play a vital role in nutrient cycles such as nitrogen cycle, Bacteria such as nitrobacter and nitrazomonas helps in mineralization of nitrogen which is necessary for uptake of nitrogen by plant. Addition of acidic fertilizers in high doses can affect the soil $\mathrm{pH}$. Increased soil $\mathrm{pH}$ affects the growth of the plant and decrease the crop yield due to stunted growth and poor plant vigour. It causes soil pollution because it amends its physical, biological and chemical characteristics. Soil health is compromised due to excessive use of chemical fertilizers. Chemical fertilizers can also cause global warming as they can produce green house gases. Chemical fertilizers can also cause nutrient toxicity as farmers can apply fertilizers more than required and this causes increase of particular nutrient which causes the toxicity. This can hinder the uptake of other nutrients in plant and causes various toxicity and deficiency symptoms in plant. These toxicity symptoms can include chlorosis and necrosis. In chlorosis, yellow colouration occurs in leaves and in necrosis the death of the plant tissue, can occur both of these can adversely affect the growth of the plant. The prolonged use of chemical fertilizers can also cause the compaction of soil as they seep to the subsoil and form hard pan by interacting with clay. Ultimately the quality of the food produced is degraded as the essential mineral and vitamin are less and toxic substances can accumulate in the crop produced which affects human health. One major disadvantage is eutrophication and which leads to water pollution. The long term use of chemical fertilizers can deplete the soil off nutrient. There are numerous disadvantages of chemical fertilizer as the soil can take really long to replenish and attain its natural form. Soil need to be fit as it is most important factor for growth of plant. Due to the decrease in soil quality farmers have started using alternate substances such as biofertilzers which provide right amount of nutrients and are eco-friendly.

\section{Biofertilizers}

Biofertilizers consist of microorganisms which can supply adequate nutrient to the plants and does not deteriorate the quality of the soil. They are also known as microbial inoculants. Biofertilizers can mobilise the nutrient present in the soil and make it available for uptake by plant through biological process. Biofertilizers are used extensively as an eco friendly approach to minimize then use of chemical fertilizers, improve soil fertility status and for enhancement of crop production by their biological activity in the rhizosphere in last one decade (Selvakumar et al., 2009). The biofertilizers are the preparation which contains live or latent cell of different strains of micro organism. These organisms are found in nature. They are produced on a large scale for commercial production and sold in the market. Their production requires technical assistance as micro organism requires favourable environment to grow. Biofertilizers are either applied on the seed or in soil. Biofertilizers may be classified as carrier based inoculants fixing atmospheric nitrogen or by stimulating plant growth through synthesis of growth promoting substances (Asad et al., 2004). They play a very important role in vigorous growth of the 
plant and enhancing the soil fertility. Biofertilizers offer a cheaper low capital intensive and eco friendly route to boosting farm productivity depending upon their activity of mobilizing different nutrients (Koushal et al., 2011). Micro organism play an important role in mobilizing the nutrients present in the soil as nutrients in the soil are present in mineral form. But due to loss in quality of the soil, the number of micro organism becomes less in the soil. (Pramanik et al., 2012) revealed that inoculation of biofertilizers significantly improved growth parameters like plant height yield parameters like number of pods per plant, weight of pods per plant, number of gains per plant, test weight, grain yield, stalk yield and harvest index. The main role of the biofertilizers is to mobilize the nutrients present in the soil as they contain those microorganisms. Most importantly the use of biofertilizers is a sustainable way of achieving the desired production as these does not harm available resources. The quality of soil is well maintained by the use of biofertilizers. They can increase the yield up to 30 percent. Biofertilizers also helps to develop a strong root system and overall growth of the plant is better. It helps plant to thrive under unfavourable condition and the plants can live longer. They are cost effective and the price of biofertilizers is less when compared to the chemical fertilizer so farmers can easily buy them. They can also help reduce shock during transplantation as this is a major issue. Moreover use of biofertilizers is cheap and really effective and can increase the farm income.

\section{Why legume crops}

Legumes are considered to be the cheapest source of protein. They are an important cash crop and are integral part of the vegetarian diet. They play a very important role in organic farming as they are used in crop rotation. As legumes are deep rooted crops so they can make available the nutrients present at lower level and can also fix the atmospheric nitrogen by symbiotic association with Rhizobium bacteria. One of the most important pulse crops is mungbean; it has the potential to enrich soil through atmospheric nitrogen fixation and can also minimize the scarcity of fodder because the whole plant or its by-products can be used as good animal feed (Rana et al., 2011). These crops can be also used for green manuring which can help improve the soil productivity. In India, pulses accounts for a large part of export and provide good financial gains. The total amount of protein present in the pulses is 20 to 25 percent by weight. Pulses are one of the important segments of Indian agriculture after cereals and oil seeds with 33 percent of the world's area and 22 percent of the production (Kant et al., 2016).

\section{Rhizobium}

Rhizobium is a nitrogen fixing bacteria. The symbiotic association between Rhizobium and roots of legume plants leads to the fixation of the nitrogen. Nitrogen is considered important.

For plant growth and termed as a macro nutrient because plant requires it in a large quantity.

Rhizobia play an important role in reducing molecular nitrogen into ammonia this process is known as nitrogen fixation (Htwe et al., 2019). Rhizobium fixes $50-100 \mathrm{~kg}$ nitrogen per hectare so it is agronomically important as it reduces the use of chemical fertilizer. It belongs to Rhizobiaceace family. It is mainly applied to the seed of the legume crop before sowing. It is a gram negative and motile bacterium with non sporulating rods. For expression of the nitrogen fixing genes present in Rhizobium it requires a host plant 
as it cannot fix nitrogen independently. The symbiotic relation of the legume and Rhizobium is facultative as both species derive benefit from each other but not being fully dependant and can survive without each other and this relation is mainly initiated by starvation of host plant. Different strain of Rhizobium is required for different legume crop as for successful nodulation a compatible strain of the bacteria is required. Nodules are formed after the bacteria colonize forms a tumour like structure, which helps in ammonia production. It can be used for pulses like red gram, black gram, soybean, chickpea, pea, lentil, etc. Use of biofertilzer with some other organic amendment can reduce the use of chemical fertilizer and can restore the quality of the soil. (Fatima et al., 2007) concluded that increase in soybean yield can be achieved by applying Rhizobium mixed culture with phosphorous, which also improves soil fertility for sustainable agriculture. Application of the proper strain of the Rhizobium resulted in increased nodulation, acquisition of the nitrogen and increased yield. (Giri et al., 2010) obtained that, the bacterized seeds showed, 14.06 percent in total length over control, increase of 10.83 percent in total weight over control and an increase of 9 percent on germination over control. (Tahir et al., 2009) revealed that application of Rhizobium alone or in combination with Phosphorous and Nitrogen increased nodulation in soybean. Use of Rhizobium can help decrease the environmental population caused due to excessive use of chemical fertilizer.

\section{Phosphate solubilising bacteria}

Phosphorous is known as the master key element in crop production. It plays an important role in pulses in root proliferation. The nutrient content and crop production is greatly influenced by application of right level of phosphorous. Phosphorous is greatly known for the energy transfer. It is constituent of majority enzymes, nucleic acid, Adenosine triphosphate, nicotinamide adenine dinucleotide phosphate. It stimulates early growth of root and helps the seedling to establish. It also helps promoting seed and fruit formation. It also enhances the nodulation and nitrogen fixation by legumes. Phosphorous also promotes nutrient use efficiency and helps in efficient portioning of photosynthates between source and sink. Source being the leaves where photosynthesis is performed and sink where the photosynthates are transferred so it helps in biomass production. Phosphorous is an important macro nutrient and plays a vital role in metabolism of the plant. Phosphate solubilising bacteria is used to solubilise the organic form of phosphate in available form by acidification, chelate the cations bound to phosphate, and production of gluconic acid and exchange reaction. There are different strains of phosphate solubilising bacteria present. Most of the PSB strains can improve the root and shoot growth in a pulse if compared to chemical fertilizer (Vikram et al., 2008). Phosphate solubilising bacteria can be abundantly found in soil and the rhizosphere. These can contain aerobic and anaerobic strains of the bacteria. Inoculation of the phosphate solubilising bacteria can improve the yield of the crop and also increase uptake of phosphorous in the plant. Phosphatic fertilizers are expensive and their demand is higher than their supply (Budd et al., 2013). The availability of phosphorous increases in the soil by applying phosphate solubilising bacteria. Phosphate solubilising bacteria can save up to 50 percent of crop requirement of phosphatic fertilizer. Pseudomonas and microbacterium strains are found highly efficient phosphate solubilizer. Singh et al., (2018) resulted that application of phosphorous at $60 \mathrm{~kg}$ per hectare, sulphur at $20 \mathrm{~kg}$ per hectare and seed inoculation with Phosphate solubilising bacteria and 
Rhizobium significantly increased the growth, dry weight, number of nodules per plant and yields of chickpea over the control. (Singh et al., 2015) concluded that inoculation of Rhizobium and Phosphate solubilising bacteria along with $20 \mathrm{~kg} \mathrm{P}_{2} \mathrm{O}_{5}$ may be recommended for better performance in summer mungbean. Abundance of phosphate solubilising bacteria in the rhizoshpere enhances the bio availability of phosphate to the crops, it provide stimulated shoot and root growth and also increases their length, and enhance fresh an dry weight of the shoot. There is a significant enhancement in dry matter and grain yield.

\section{Azospirillum}

It is a gram negative to gram variable bacteria, heterotropic and associative in nature and is curved rod shaped and motile bacteria. They have nitrogen fixing ability of about 20 to $40 \mathrm{~kg}$ per hectare. Most widely used Azospirillum strain is Azospirillum brasilense and A.lipoferum. They have the ability to form an associative symbiosis with many plants. It belongs to the family spirilaceae. It has been reported that Azospirillum brasilense have the ability to restrict proliferation of other non pathogenic bacteria present in the rhizosphere this antibacterial activity can be due to its ability to produce bacteriocins and siderophores. Azospirillum can synthesis phytohormones can perform nitrogen fixation and nitrate reductase activity and also enhance the mineral uptake. (Burdman et al., 1996) showed that Azospirillum brasilense $\mathrm{Cd}$ inoculation promoted root hair formation in seedling roots and significantly increased total and upper nodule numbers at different concentration of Rhizobium inoculums. Azospirillum also caused an increase in the secretion of nod gene inducing flavanoids in Phaseolus vulgaris. (Puente et al., 2019) revealed that foliar application of A. brasilense on soybean had great effect on growth and nodulation, and grains harvested had higher nitrogen and protein content. After the association with the plant some biochemical changes occur in the roots, which promote plant growth and drought tolerance. In legume crop the application of Azospirillum is done with other biofertilizer such as Rhizobium to increase the growth and yield of the crop. (Burdman et al., 1996) revealed that field inoculation with Azospirillum brasilense strain $\mathrm{C}$ increased nodule dry weight (90\%), plant growth parameters and seed yield (99\%) and combined inoculation with Rhizobium and Azospirillum resulted in a further increase (23\%) in chickpea.

\section{Azotobacter}

Azotobacter is a free living, aerobic, gram negative, motile bacteria which is heterotrophic in nature. They are capable of fixing atmospheric nitrogen at an average of $20 \mathrm{~kg}$ per hectare. They are oval or spherical and pleomorphic, they form a thick walled cysts and may produce slime in large quantities. These bacteria can produce anti fungal antibiotics which can inhibit the growth of the several pathogenic fungi. (Ara et al., 2009) indicated that combine effect of BradyRhizobium and Azotobacter significantly increased nodulation, root and shoot weights at 35 days after sowing, and number of seeds per pod and seed yield were also increased in mungbean. Azotobacter population can be affected by soil physical, chemical and microbiological properties. (Dashadi et al., 2011) showed that co inoculation of Rhizobium and Azotobacter increased total nitrogen content, nodulation, seed yield and biological yield under water deficit condition. They can increase crop productivity. In legumes there significant affect can be seen when applied with other biofertilizer. 


\section{Mycorrhiza}

Mycorrhiza is a symbiotic association between the roots of plant and fungal hyphae which is a non pathogenic relationship and connection between the soil and root. In this symbiotic relationship, the fungi obtain carbon compounds and other nutritional requirements from the plant roots, and in return it provides plant with the most of the mineral element which are immobile such as Nitrogen, Phosphorous, Potassium, Calcium, Copper and Zinc from the soil solution, so its becomes a significant component in lowinput agricultural systems. Vesicular arbuscular mycorrhiza is an Endomycorrhiza as is penetrates deep in plant cells providing dome special structures as a mean of nutrient exchange and used as a biofertilizer. Arbuscular Mycorrhiza is zygomycetes belonging to the order Glomales. It is known that the nitrogen fixing ability of Rhizobium may enhance if the plant is also in a symbiotic relationship with arbuscular Mycorrhizae (Mohammadi et al., 2011). (Farrzaneh et al., 2011) generalised that across their trial period of two years that concentration $P$ concentration was higher in chickpea than the control plants. (Djebali et al., 2010) observed that at species level there as a positive effect of inoculation. There was a notable increase of shoot fresh weight, number of nodules and root dry weight was observed in bean, pea and alfalfa and most positive effect in medicago line, which showed an increase in shoot and root dry weights, in nodule and pod numbers, and an early blooming. Mycorrhizae show a positive effect on root growth of the plant which results in overall growth of legume plant.

In conclusion, biofertilizers are important tool of organic farming. Biofertilizers are proven to be effective in increasing the soil fertility without harming the health of the soil. They provide beneficial nutrients to the plant and can be used as an alternative to chemical fertilizers. There is significant effect of Biofertilizers on growth, nodulation, nitrogen fixation and yield of legume plants. As the efficiency of phosphate fertilizers is very low, inoculation with phosphate solubilising bacteria can help in mobilisation of nutrients. Rhizobium proficiently increases number of nodules and nitrogen fixation in legumes. Biofertilizers have the ability to increase the productivity of the crop in a sustainable way.

\section{References}

Abdel Ghany, T.M., M.M. Alawlaqi and M.A. Al Abboud (2013). Role of biofertilizers in agriculture: a brief review. Mycopath, 11(2): 95-101.

Aung Zaw Htwe, Seinn Moh Moh, Khin Myat Soe, Kyi Moe and Takeo Yamakawa (2019). Effects of Biofertilizer Produced from BradyRhizobium and Streptomyces griseoflavus on Plant Growth, Nodulation, Nitrogen Fixation, Nutrient Uptake, and Seed Yield of Mung Bean, Cowpea, and Soybean. Agronomy 2019, 9, 77; doi:10.3390/agronomy9020077.

Dashadi, M., H. Khosravi, A. Moezzi, H. Nadian, M. Heidari and R. Radjabi (2011). Co-Inoculation of Rhizobium and Azotobacter on Growth of Faba bean under Water Deficit Conditions. American-Eurasian J. Agric. \& Environ. Sci., 11 (3): 314-319.

Djébali, N., S. Turki, M. Zid and M. R. Hajlaoui (2010). Growth and development responses of some legume species inoculated with a mycorrhizabased biofertilizer. Agriculture and Biology Journal of North America. Print: 2151-7517.

Farrzaneh, M., H. Vierheilig, A. Losssh and H.P. Kaul (2011). Arbuscular mycorrhiza enhances nutrient uptake in chichpea. Plant Soil Envron., 57, (10): 
465-470.

Khosro Mohammadi, Shiva Khalesro, Yousef Sohrabi and Gholamreza Heidari (2011). A Review: Beneficial Effects of the Mycorrhizal Fungi for Plant Growth. J. Appl. Environ. Biol. Sci., 1(9)310-319.

Majid Mahmood Tahir, M. Kaleem Abbasi, Nasir Rahim, Abdul Khaliq and Mushtaq Hussain Kazmi (2009). Effect of Rhizobium inoculation and NP fertilization on growth, yield and nodulation of soybean (Glycine max L.) in the sub-humid hilly region of Rawalakot Azad Jammu and Kashmir, Pakistan. African Journal of Biotechnology Vol. 8 (22), pp. 61916200.

Mariana L. Puente, Myriam Zawoznik, Marcelo López de Sabando, Gonzalo Perez, José L. Gualpa, Susana M. Carletti and Fabricio D. Cassán (2019). Improvement of soybean grain nutritional quality under foliar inoculation with Azospirillum brasilense strain Az39. Symbiosis, 77:41-47.

Mishra, D.J, Rajvir singh, U.K. Mishra and Shahi Sudhir Kumar (2012). Role of Bio-Fertilizer in Organic Agriculture: A Review. Research Journal of Recent Sciences, 2277-2502 Vol. 2, 39-41.

Moin Uddin, Sajad Hussain, Mohammad Masroor Akhtar Khan, Nadeem Hashmi, Mohammad Idrees, Mohammad Naeem and Tariq Ahmad Dar (2014). Use of $N$ and $P$ biofertilizers reduces inorganic phosphorus application and increases nutrient uptake, yield, and seed quality of chickpea. Turk J Agric, 38: 47-54

Nazmun Ara, M. Rokonuzzaman and M.N. Hasan (2009). Effect of BradyRhizobium and Azotobacter on growth and yield of mungbean varieties. J. Bangladesh Agril. Univ. 7(1): 7-13.
Nishita giri and Naveen Chandra Joshi (2010). Growth and yield response of chick pea (Cicer arietinum) to seed inoculation with Rhizobium sp. Nature and Science, 8(9).

Pramanik, K. and A. K. Bera (2012). Response of biofertilizers and phytohormone on growth and yield of chickpea (Cicer arietinium L.). Journal of Crop and Weed, 8(2):45-49.

Rajneesh Singh, Tej Pratap, Durgesh Singh, Ghanshyam Singh and Abhinav Kumar Singh (2018). Effects of phosphorus Sulphur and biofertilizers on growth attributes and yield of chickpea (Cicer $\begin{array}{lll}\text { arietinum } & \text { L.). Journal of }\end{array}$ Pharmacognosy and Phtochemistry; 7(2): 3871-3875.

Rana, M.M., A. K. M. S. H. Chowdhury AND M. S. U. Bhuiya (2011). Effects ofPlant Population and Biofertlizers on the Growth Parameters of three summer Mungbean (Vigna radiata L.). Cultivars Bangladesh J. Agril. Res. 36(3): 537542.

Ranjit Chatterjee and Subhendu Bandyopadhyay (2017). Effect of boron, molybdenum and biofertilizers on growth and yield of cowpea (Vigna unguiculata L. Walp.) in acid soil of eastern Himalayan region. Journal of the Saudi Society of Agricultural Sciences, 16, 332-336.

Saed Ahmad Asad, Asghari Bano, Muhammad Farooq, Muhammad Aslam and Aftab Afzal (2004). Comparative Study of the Effects of Biofertilizers on Nodulation and Yield Characteristics of Mung Bean (Phaseolus vulgaris L.). International Journal of Agriculture and Biology, 1560-8530/06-5-837-843.

Sanjay Koushal and Parbjeet Singh (2011). Effect of Integerated Use of Fertilizer, FYM and Biofertilizer on Growth and Yield Performance on Soybean (Glycine $\max (\mathrm{L})$ Merill). Research Journal of 
Agricultural Science, 43 (3).

Saul Burdman, Hanne Volpin, Jamie Kigel, Yoram Kapulnik and Yaacov Okon (1996). Promotion of nod Gene Inducers and Nodulation in Common Bean (Phaseolus vulgaris) Roots Inoculated with Azospirillum brasilense Cd. Applied and Environmental Microbiology, p. 3030-3033 Vol. 62, No. 8

Saul Burdman, Shlomo Saric, Jamie Kigel and Yaacov Okon (1996). Field Inoculation of Common Bean (Phaseolus vulgaris L.) and Chick Pea (Cicer arietinum L.) with Azospirillum brasilense Strain Cd. Symbiosis, 21, 4148.

Selvakumar, G., M. Lenin, P Thamizhiniyan and T. Ravimycin (2009). Response of biofertilizers on the growth and yield of Blackgram (Vigna mungo L.). Recent Research in Science and Technology, 1(4): 169-175.

Shishu Pal Singh, Adesh Kumar, Ram Bhasose and Suresh Kumar (2015).
Response of summer Mungbean to Phosphorous and Biofertlizers in Eastern Uttar Pradesh. Annals of Plant and Soil Research 17 (1): 104-105.

Surya kant, Achin kumar, Satendera kumar, Vipin Kumar, Yogesh Pal and Anil K shukla (2016). Effect on Rhizobium, PSB and P-levels on growth, yield attributes and yield of urdbean (Vigna mungo L.). Journal of Pure and Applied Microbiology, Vol. 10(4), p. 30933098.

Vikram, A. and H. Hamzehzarghani (2008). Effect of phosphate solubilisng bacteria on nodulation and growth parameters of greengram (Vigna radiate L. Wilczek). Research Journal of Microbiology 3(2): 62-72.

Zarrin Fatima, Muhammad zia and M. Fayyaz Chaudhary (2007) Interactive effect of Rhizobium strains and $\mathrm{P}$ on soybean yield, nitrogen fixation and soil fertility. Pak. J. Bot., 39(1): 255-264.

\section{How to cite this article:}

Hardika Kaushal and Sarvjeet Kukreja. 2020. The Effect of Biofertilizers on Growth and Yield of Legumes - A Review. Int.J.Curr.Microbiol.App.Sci. 9(11): 2606-2613.

doi: https://doi.org/10.20546/ijcmas.2020.911.315 